\title{
Spatiality of COVID-19 Infections in Ahmedabad: An Early Period Analysis ${ }^{1}$
}

\author{
Darshini Mahadevia ${ }^{2}$, Manish Datt ${ }^{3}$, Bhargav Adhvaryu ${ }^{4}$, and Suhair Killiyath ${ }^{5}$
}

\begin{abstract}
The Coronavirus disease (COVID-19), that has gripped the world since December 2019 and declared a pandemic has infected about 4.8 million people in India and counting. This pandemic is urban-centric globally and in India in the earlier stages. In this paper we argue that the virus's spread in India has multiple routes, the housing conditions, socio-economic characteristics as well as the epidemiology route that influences the management of the infection contrary to attributing the spread geography to only vulnerable areas. Selecting Ahmedabad, a city that register higher number of infections in the early period, this paper attempt to understand the pattern of infection spread and explain these using recorded infections from March 17, 2020 to June 10, 2020 period.
\end{abstract}

Key words: COVID-19; Ahmedabad; Infection Geography; Spatial Analysis

\section{Introduction}

The Coronavirus disease (COVID-19) caused by the severe acute respiratory syndrome coronavirus 2 (SARS-CoV-2) that has gripped the world since December 2019, leading to more than 27 million infections and close to 870,000 deaths globally by the first week of September $2020^{6}$ and counting, is very much an urban pandemic (Mishra et al., 2020). The virus originating in Wuhan China spread rapidly to the rest of the world, including in India, since Feb 15, 2020 introduced through returnees from China, European countries, and the United States of America. By March 20, 20207 the its rapid spread in India led to announcement of a lockdown from March 24, 2020 that continued till May 17, 2020 in the whole country and different phases of unlock unfolding thereafter across the country, in sporadic, localised and often unplanned to control the spread of the infection; none of which seem having any impact on the spread ${ }^{8}$, with total infections in India crossing 4.1 million by the first week of September $2020^{9}$. The UN-Habitat's data suggests that $95 \%$ of the total cases were located in the urban areas (UN-HABITAT, 2020) and the World Health Organisation (WHO) stating that the first transmission occurred in the megacities connected internationally (WHO, 2020). The high densities and crowded living conditions of the cities, particularly in the developing countries such as India, represented by vulnerability index

\footnotetext{
1 This research paper's support is from the Ahmedabad University Seed Grant to Prof. Darshini Mahadevia and Prof. Manish Datt.

2 Professor and Associate Dean, Arts, School of Arts and Sciences, Ahmedabad University

(darshini.mahadevia@ahduni.edu.in)

${ }^{3}$ Assistant Professor, Biological and Life Sciences, School of Arts and Sciences, Ahmedabad University

(manish.datt@ahduni.edu.in)

4 Professor of Urban Science, Amrut Mody School of Management, Ahmedabad University (bhargav@cantab.net)

${ }^{5}$ Research Assistant, School of Arts and Sciences, Ahmedabad University (suhairkilliyath@gmail.com)

${ }^{6}$ See: https://www.worldometers.info/coronavirus/ (accessed on July 1, 2020).

7 See: https://www.worldometers.info/coronavirus/country/india/ (accessed on May 15, 2020).

8 See: https://indianexpress.com/article/business/economy/unplanned-localised-lockdowns-did-little-to-check-spread-ofcovid-led-to-increased-economic-uncertainty-6585764/ (accessed on September 7, 2020).

9 See: https://www.worldometers.info/coronavirus/ (accessed on July 1, 2020).
} 
(Mishra et al., 2020) has been attributed to the infection's rapid spread. However, as time went by, the infections have spread across different city sizes as well as in the parts of the city less vulnerable in India, raising several questions about its epidemiology and containment.

One line of enquiry and hence its containment is pointing towards UN-Habitat's housing and urban planning agenda (Hood, 2005; Mishra et al., 2020; Patel, 2020). Poor housing creates higher vulnerability to many diseases due to multiple deprivations (Patel et al., 2014, 2020, Hirway \& Mahadevia, 2020). Another line of enquiry is the epidemiology line.

This SARS-CoV-2 (COVID-19) virus is known to spread through droplets originating from an infected individual when they speak, cough, or sneeze. This was confirmed at the early stages of the outbreak when the virus particles were detected from the naso/oro-pharengeal regions of the COVID-19 positive individuals, strongly warranting the practice of social (physical) distancing to check the spread of this disease through person-to-person transmission ${ }^{10}$. The droplets coming out of the infected individuals are rather heavy particles which cannot travel a long distance (Jayaweera et al 2020), hence its higher probability of spread in dense living conditions. Recently there has been debates around the SARS-CoV-2 being air borne, with increased chances of its spread in conditions such as poor ventilation, overcrowding, etc. or if physical contact increase due to taking up of normal activities.

Another route through which this virus can spread is through fomites (i.e. objects that may be contaminated with infectious agents and serve in their transmission). The SARS-Cov-2 virus can stay viable on fomites such as stainless steel and plastic surfaces for up to three days (Doremalen et al., 2020). Thus, if an infected individual contaminates a surface, which is then contacted by a susceptible individual there is a chance of the individual may acquire virus from that fomite.

In addition to aforementioned routes of transmission, another factor that critically affects transmission dynamics is the viral load (total amount of virus) within the infected individual. A Indian Council of Medical Research (ICMR)-National Institute of Occupational Health (NIOH, Ahmedabad) study shows that infected individual with higher viral load are about eight times more likely to spread the virus compared to individual with a low viral load (Sarkar et al., 2020).

In this paper we argue that the virus's spread in India has multiple routes, the housing conditions, socio-economic characteristics as well as the epidemiology route that influences the management of the infection contrary to attributing the spread geography to only vulnerability index as Mishra et al. (2020) do. Selecting Ahmedabad, a city of 6.5 million in 2011, this paper attempt to understand the pattern of infection spread and explain these using recorded infections from March 17, 2020 to June 10, 2020 period. Ahmedabad is among the cities with the higher number of infections in the early period of pandemic spread with a high Case Fatality Rate (CFR). In India, the CFR as on June 29, 2020 was $2.97^{11}$ whereas in Ahmedabad it was $7.05^{12}$. The authors are located in the city and hence have collected the data over the period from different sources.

10 See: https://www.cdc.gov/coronavirus/2019-ncov/prevent-getting-sick/social-distancing.html (accessed on September 14, 2020)

11 See: https://www.worldometers.info/coronavirus/ (accessed on July 1, 2020)

12 For Ahmedabad City data, see:

https://ahmedabadcity.gov.in/portal/web?requestType=ApplicationRH\&actionVal=loadCoronaRelatedDtls\&queryType=Se lect\&screenld=114, (accessed on July 1, 2020). 
During this period, Ahmedabad city was under different phases of lockdown aligned with the national level directions. The first lockdown was citywide from March 25 to April 14, 202013. The second was from April 15 to May 3, 2020, which continued to be stringent in central, eastern and southern parts of the city, while allowing mobility to access basic needs such as grocery shops, fruit and vegetable stalls, and medicines in other parts. The infections continued to rise that led to a third lockdown from May 4 to May 17, 2020, which was the strictest of all not allowing distribution of any perishable food items. The fourth was from May 18 till May 31, 2020, that was relaxed in western part of the city but continued to be stringent in high-incidence areas namely, central, eastern, northern and southern zones (For zone boundaries see maps in Panels 1 and 2). Beyond May 31, 2020, some localities, called the containment zones, continued with restrictions while the rest of the city opened for daily activities and restricted functioning of offices and industries. The containment areas have shifted in response to the rise in infections and hence the infections' geography has also shifted over time, as an after effect of allowing mobility and hence increased contacts. The infection spread shifts away from dense and vulnerable areas to areas of urban sprawl and high-income areas.

In this paper studies two aspects. First, we show general characteristics of those infected, followed by mapping the infection geography based on the reported data, disaggregated by seven zones across the city. We show how the infections have shifted geographies over time, in response to the lockdown relaxations. Since the virus spreads through contact, higher the mobility (expected during relaxation in lockdown), higher is the contact and higher are the chances of infections. We present the infection pattern disaggregated by time and space. Second, we attempt statistical explanation of infections using demographic variables from the population census and from the infection data, disaggregated by time and space.

Section 2 discusses the epidemiology of COVID-19 spread in general and identifying factors causing its spread in general and in the cities in India. This section helps us in identifying the explanatory variables for our statistical analysis. Section 3 introduces Ahmedabad city, discuss the specific methodological issues related to data on COVID-19, and discuss the socio-economic profile of those infected. Section 4 presents the spatio-temporal pattern of COVID-19 infections in the city. Section 5 explains the causal factors of infection concentrations in certain geographic areas leading to the last section that discusses policy issues as well as identifies areas of further research.

\section{Epidemiology of COVID-19}

The epidemiology of COVID-19 virus is a work in progress. This virus remains highly infections with the Reproduction Rate $\left(\mathrm{R}_{0}\right)$ estimates ranging from 1.4 to 3.5. The early WHO estimate of Reproduction Rate was 1.4 to 2.5. "All the estimates of transmissibility indicate that self-sustaining human-to-human transmission is the only plausible explanation for the magnitude of the on-going outbreak" (Chatterjee et al., 2020). Studies have established asymptomatic transmission of this virus (Bai et al., 2020; Chan et al., 2020). Thus, "persons with epidemiological risk exposure should practice strict adherence to standard precautions and control of contact-based transmission."

13 The first lockdown was announced at 8.00 pm on March 24, to be in effect from 12.01 am for March 25, 2020. 
(Chatterjee et al 2020: 5). Chatterjee et al (2020) suggest that symptomatic patients in the community setting should be discouraged from congregating in the public or crowded areas.

Vulnerability to COVID-19, as per the early studies, for example by (Fauci et al., 2020) show that: (i) the median age of the infected population was 59 years, (ii) morbidity and mortality was high among the elderly and those with coexisting conditions, (iii) 56 per cent males (probably because they are more likely to be out in public domain than women), (iv) children are less likely to be infected or had mild infection, in other words their infection may not have become a disease, (v) the Case Fatality Rate (CFR), what is also called Infection Fatality Rate (IFR) was 2 per cent (in China) but more recently found to be less, $1.4 \%$ (Guan et al., 2020) or even less than 1\% if asymptomatic cases were included and (vi) its $\mathrm{R}_{0}$ was 2.2 .

The higher prevalence of the disease has been in the urban areas. For example, in Spain, a serological survey found the prevalence rate was more than $10 \%$ in and around Madrid and less than $3 \%$ in the coastal areas ${ }^{14}$ (Pollán et al., 2020) Urban areas are dense human settlements, providing opportunity for close physical interactions among people. Urban areas are also characterized by limited public space making life during the lockdowns for social distancing to keep the cases down, very difficult to bear. Social distancing, the most effective mitigation strategy for COVID-19 (Gu et al., 2020; Tian et al., 2020; Wilder-Smith \& Freedman, 2020), but it is a disruptor of everyday life causing its prolonged enforcement difficult, causing to people to violate the required measures and thereby re-spreading the infection .

Certain ethnic groups are more susceptible than others due to their employment profile. For example, in Northern Nevada in the USA (during March 12 and May 8, 2020), among 172 COVID-19 patients 50.6\% were Hispanic, whose mean age among infected was 46 years whereas the non-Hispanics infected had mean age of 55.8 years, although they had more co-morbidities such as hypertension, obesity, and chronic obstructive pulmonary disease. But Hispanics were more likely to live in low-income communities than then the non-Hispanics (Antwi-Amoabeng et al., 2020)

Five southern states in India show strong positive relationship between population density and COVID-19 infections (Arif \& Sengupta, 2020). Indian cities' water and sanitation coverage is lagging, leading to (Das et al., 2020) arguing that poor availability and accessibility of water, sanitation, and hygiene (WaSH) may increase risk of COVID-19 spread. Availability of these services in the deprived areas of large cities in India is very poor, wherein, research states that these have higher incidences of infectious diseases such as diarrhoea, cholera, typhoid and hepatitis (Ezeh et al., 2017). Khatua (2020) argues that slum areas in the Indian cities, giving example of Kolkata, do not just have high density, but also have crowded living with small rooms often without any ventilation and more than five people living in less than $10 \mathrm{sq} \mathrm{m}$ rooms. The slum settlements also do not have large open spaces wherein people when out can maintain social distance. The water supply, bathrooms and toilets are often shared. These are conditions very well suitable for the spread of COVID-19 virus. In vertical housing too, especially the various slum redevelopment and resettlement sites, including the housing under the PMAY (Pradhan Mantri Awas Yojana $)^{15}$, the potential for virus spread is very high due to these being one-room dwelling units. Singh \& Adhikari (2020), show that in India, the presence of three-generation households,

\footnotetext{
14 This was a survey from April 27 to May 11, 2020 of 35,883 selected households from the municipal rolls in which 61,075 participants or $75.1 \%$ of those contacted responded.

${ }^{15}$ An affordable, social housing project sponsored by the federal government of India
} 
that is presence of children, parents and grand-parents in the same household increases the transmission of contagion from the children to the grand-parents, which is not a situation in other countries. And hence, lockdown tends to increase the vulnerability of the elderly in multigenerational households.

The extent and rate of spread of COVID-19 is a function of demographic and socioeconomic profiles of the population, among other things. Initial epidemiological analysis of COVID-19 patients revealed a direct correlation between chances of infection and age of the individual. Elderly populations are at a significantly higher risk of getting infected as compared to the younger populations, and particularly the children (Davies et al., 2020). The outcomes of COVID-19 infection also vary with age such that individuals over 65 years have 23-fold higher death risk than those on the other side (Davies et al., 2020). An additional level of complexity arises because of the existence of comorbidities in older individuals which not only increases susceptibility but also aggravates the severity of disease in this age group significantly. About 70 percent of COVID-19 mortalities in Gujarat, are linked to comorbidities such as hypertension, diabetes, and others ${ }^{16}$.

\section{COVID-19 Infections in Ahmedabad}

\subsection{COVID-19 Infection Data Base}

The data used are of reported infections. Since the pandemic outbreak, method of registering infections has continuously changed in accordance with the state government's testing policy based on the ICMR. The infection is reported in the statistics after its confirmation through a Reverse Transcriptase Polymerase Chain Reaction (RT-PCR) test. Given that the health insurance policy coverage is low and about $85 \%$ of the healthcare expenditures are out-of-pocket expenses of the households, every symptomatic infected may not necessarily be reported in the system. Thus, the reported numbers of infections are based on those who are tested, self-reported, and detected through a thermal scanner.

Importantly, the symptomatic cases show a spectrum of severity which can range from mild symptoms that require little or no medical interventions to acute cases that require emergency care and treatment. A pre-symptomatic stage which is a consequence of the rather long incubation period of the virus compounds the issue. The symptoms for COVID-19 usually appears after about 7.7 days (median value for a range from 2 days to 2 weeks) of infection ${ }^{17}$. The data is largely of the symptomatic patients. In a study based on infector-infectee transmission pairs under controlled settings, it has been estimated that about $44 \%$ of infections were transmitted before the onset of symptoms (He et al., 2020). Thus, the data of infections are not well captured and the official data is the only source.

\footnotetext{
16 See: https://ahmedabadmirror.indiatimes.com/ahmedabad/cover-story/71-of-COVID-19-patients-who-died-hadcomorbidity/articleshow/75397214.cms, (accessed on Sept 7, 2020).

17 See: https://www.medicalnewstoday.com/articles/scientists-revise-covid-19-incubation-period-to-7-7-days (accessed on September 14, 2020).
} 


\subsection{Analysis Methods}

The data collected and analysed are for entity Ahmedabad Municipal Corporation (AMC), which is the city government. Ahmedabad is divided along religion, and caste, and class lines (Mahadevia, et al., 2014). City's estimated population in 2020 is 8.0 million in the agglomeration area $^{18}$. For monitoring the COVID-19 infections, the city compiled data for each of the 56 wards and then aggregated these into seven zones used for decentralized governance. Our analysis is at zone level wherein we describe the geography of the recorded infections and then at ward level wherein we attempt to attribute causes for infection concentration. These seven zones are: are central zone (CZ), north zone (NZ), east zone (EZ), south zone (SZ), west zone (WZ), southwest zone (SWZ), and northwest zone (NWZ).

Two sets of data have been used; one that contained name, age, sex and address of the infected individuals. This data is available for 17-03-2020 to 10-06-2020 period. Using the address, identifying the housing typology from it, we have categorized the individual as poor $(\mathrm{P})$ or nonpoor (NP). This was made possible by deep understanding of the city by the two of the authors. The second data is obtained from the newspapers that published zone level aggregate data everyday continuing up to July 14, 2020. The data is up to June 10, 2020 that allows us to observe geographic, demographic, and economic characteristics of those infected. These data when aggregated to ward level allowed us to correlate variables of housing quality and crowding, demographic variable of household size (household size is large in low-income households), population density, infrastructure such as water supply, and literacy, all made available from the population census of 2011 (Chandramouli \& General, 2011). As mentioned earlier, some scholars have used these census data at the ward level to construct vulnerability index using ward as a unit (Mishra et al., 2020; Patel et al., 2014, 2020).

For analysis of geographic pattern, we assumed that the number of infections is as much an outcome of local factors as listed above as lockdown conditions - stringent lockdown controls infected-infectee spread and vice versa. Since the lockdown conditions have differed over different periods and in different zones, we have attempted the spatio-temporal analysis by lockdown phase and zones. We have divided the registered infections of COVID-19 into five periods: (i) Period 1 (26-03-2020 to 21-04-2020) which consists of the first lockdown and seven days after, given that the impact of any lockdown or unlocking period would be up to seven days ${ }^{19}$; (ii) Period 2 (16-042020 to 10-05-2020); (iii) Period 3 (04-05-2020 to 24-05-2020); (iv) Period 4 (18-05-2020 to 06-062020 ) and (v) Period 5 (01-06-2020 to 14-07-2020), the unlock period. While the stringent lockdown continued in the $\mathrm{CZ}$ and SZ, during Period, the stringent conditions were relaxed in the WZ, SWZ and NWZ and Period 5 had no restriction of movement in these three zones.

\subsection{Socio-economic Characteristics of the Infected}

This analysis is based on individual level data up to June 10, 2020. During the entire period of the study, $52.8 \%$ infected persons were poor. However, during the strict lockdown periods (Period 1 and Period 2), early two-thirds of the infected persons were identified to be the poor (Figure 1). In the pre-lockdown period, as it is now known that the virus came to India through international

\footnotetext{
${ }^{18} \mathrm{https}: / /$ worldpopulationreview.com/world-cities/ahmedabad-population (accessed on July 24, 2020).

19 See: https://www.medicalnewstoday.com/articles/scientists-revise-covid-19-incubation-period-to-7-7-days (accessed on September 14, 2020).
} 
travellers, only three of the infected individuals were poor whereas remaining five were non-poor, with their residence in the WZ and SWZ. In the later part of Period 3, when the lockdown conditions were relaxed in western region comprising of WZ, NWZ and SWZ, the infections begun to spread to the non-poor households. This trend then continued in Period 4, when the CZ, EZ, and SZ were under strict lock-down, the three-fifths of the infected persons were non-poor. This disproves the starting point of studies such as by (Mishra et al., 2020) that the populations in the most vulnerable areas, which by the construction of the index are those inhabited by the poor, are prone to infections. The other dimensions of the spread such as lockdown restrictions, family composition (multi-generational families) and general behaviour irrespective of the income group, to contribute to the spread of this virus.

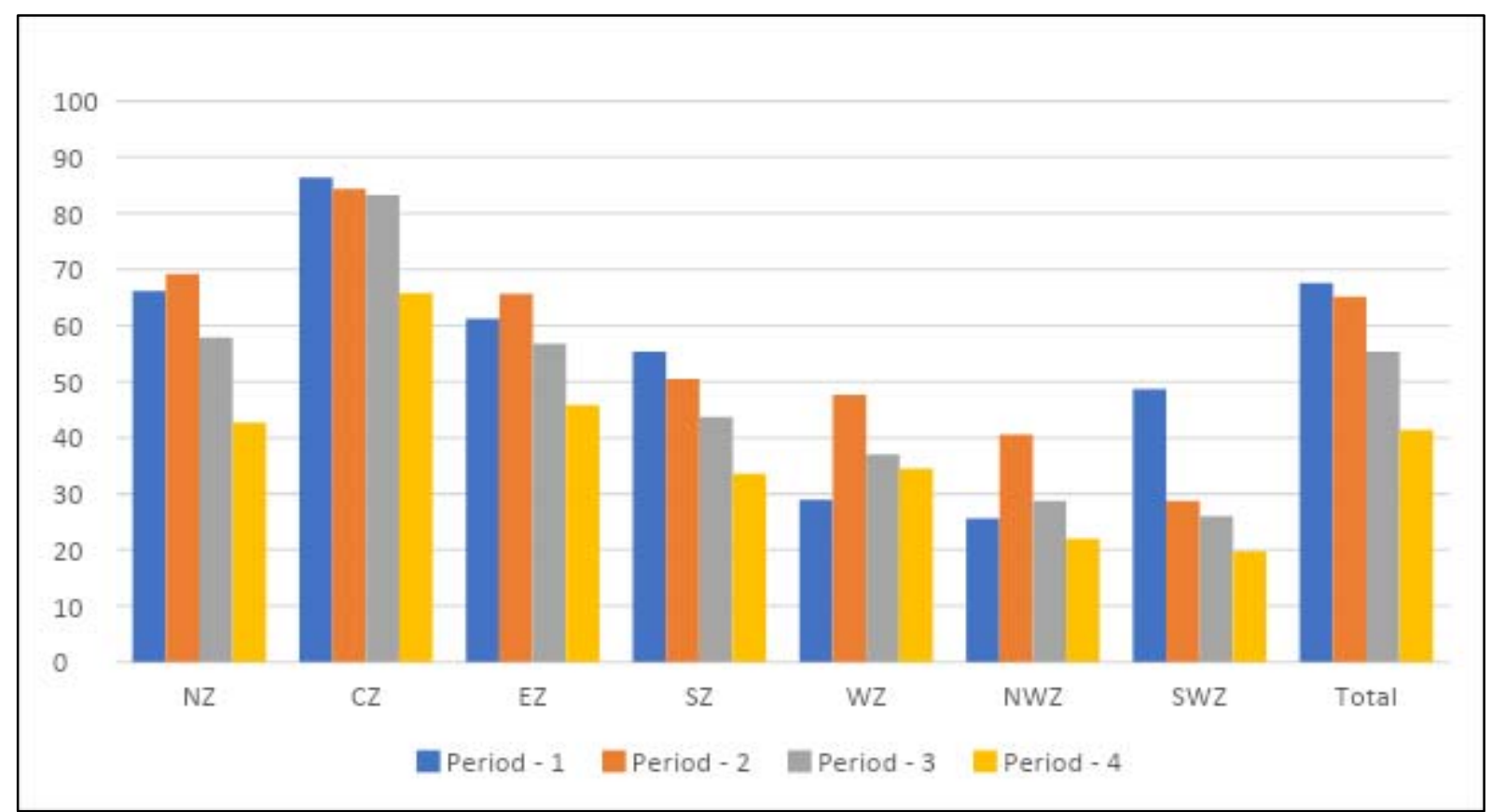

Note: Data in Figures 1, 2 and 3 and Tables 1 and 2, pertains to individuals reporting infection up to June 10, 2020 Figure 1: Percentage Poor among Infected Persons

The incidence of COVID-19 infections is higher in the males of age group 30-55, which is the core of the working age males. Whereas in females the highest frequency is found in the age group of 25-30, which is usually the age group engaged as domestic help (see Figure 2).

Figure 3, the bottom two graphs show that the incidence of COVID-19 is much higher in poor people, especially in the core age group of working males (25-35). In poor females, the incidence is highest in the age group of 20-30, which is the core age group that work as domestic help. The incidence of COVID-19 seems to be lesser for both males and females in non-poor group. This implies that the poor are more vulnerable to COVID-19 infections usually they live in more crowded conditions, have lower level of access to basic services (more importantly running water in this case), and lower financial resources to spend on medical treatment. 


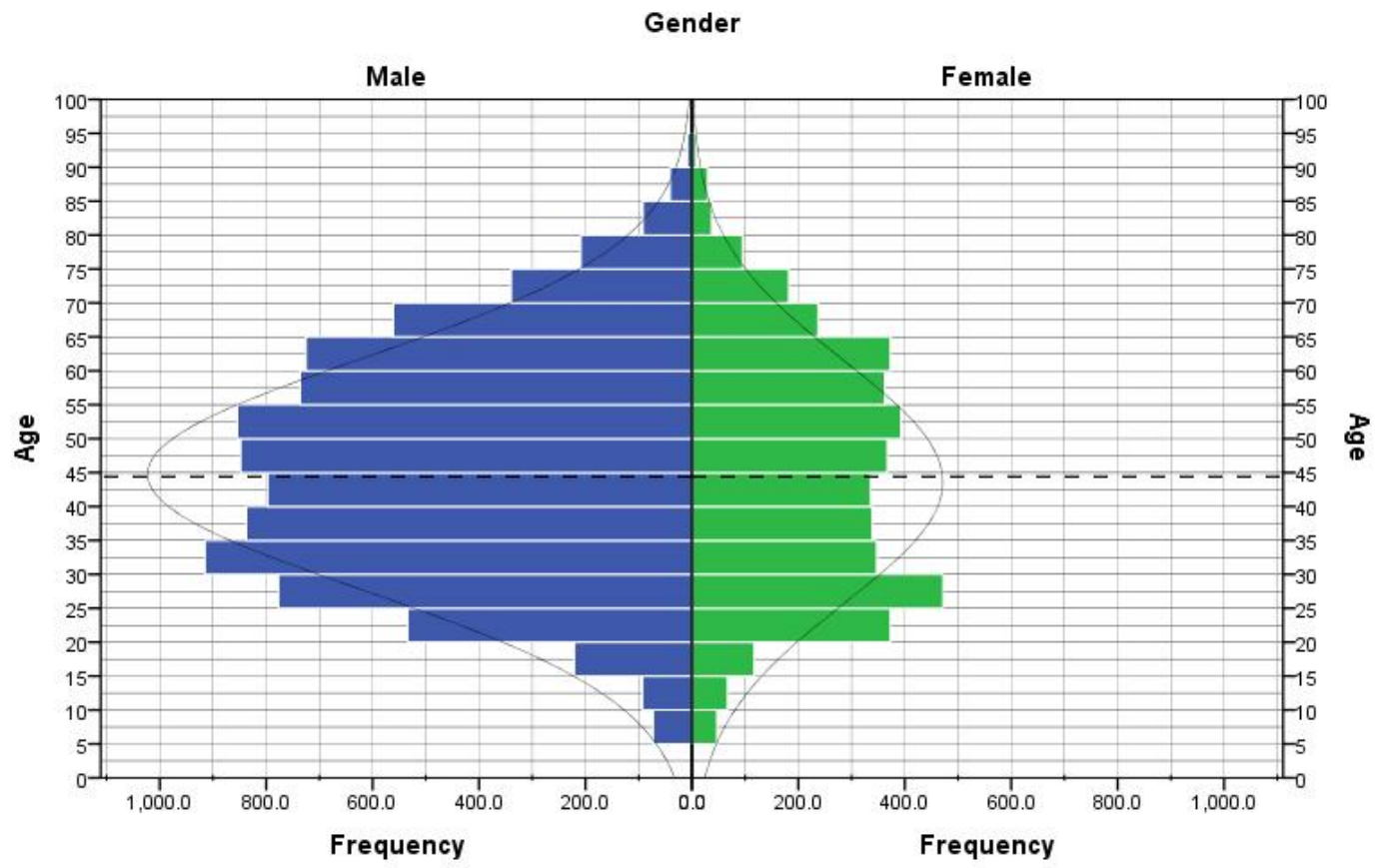

Figure 2: Covid-19 infections by age and gender

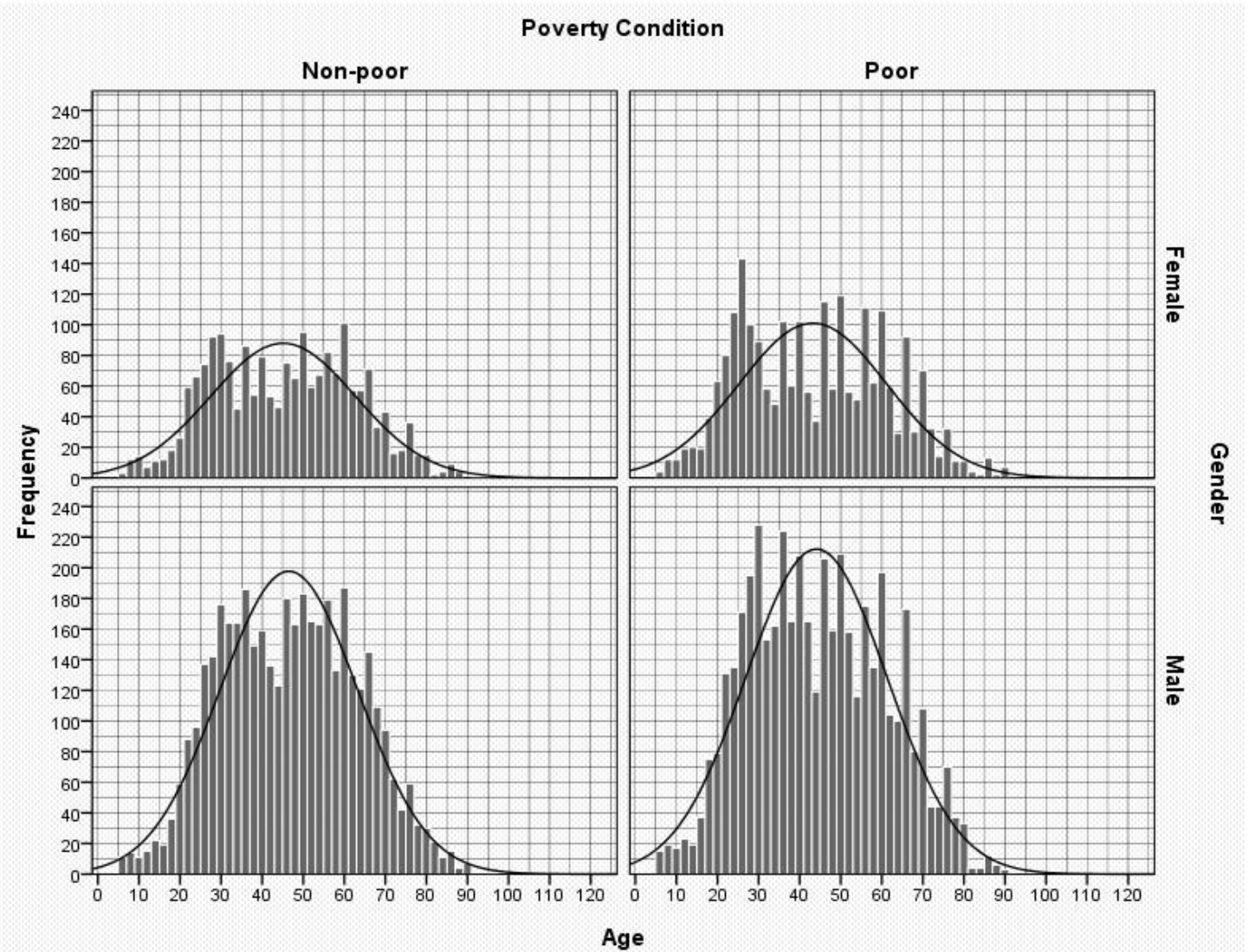

Figure 3: Covid-19 infections by age, gender, and poverty condition 
All studies show that those in age group of 60 and above are at high risk of COVID-19 infection. $19.3 \%$ of the total reporting infections were in the age group of more than 60 years (Table 1). This age group's proportion in the total population is $8.2 \%$, indicating that the persons in this age group had 2.35 times $(19.3 \% / 8.2 \%)$ possibility of getting infected than in the total population. Those in the age group less than 15 years, this ratio was 0.13 . For those in age group 16-30 years, this ratio was 0.76 and for those in age group 31-60 years, this ratio was 1.47. Thus, with the increase in the age the chances of getting infected increased. This pattern was seen across all the zones as well.

Table 1: Reported Infections by Age and District Population by Age

\begin{tabular}{|c|c|c|c|}
\hline \multirow[t]{2}{*}{ Age } & Total infected & $\begin{array}{l}\text { Population of Ahmedabad District } \\
\text { (Urban) (2011) }\end{array}$ & $\begin{array}{c}\text { Proportion in total population / proportion in } \\
\text { total infections }\end{array}$ \\
\hline & (a) & (b) & (b)/(a) \\
\hline$<15$ & 3.4 & 25.2 & 0.13 \\
\hline $16-30$ & 21.9 & 28.9 & 0.76 \\
\hline $31-60$ & 55.4 & 37.7 & 1.47 \\
\hline$>60$ & 19.3 & 8.2 & 2.35 \\
\hline Total & 100.0 & 100.0 & 1.0 \\
\hline
\end{tabular}

Table 2: Sex Ratio Among those Reported Infections by Zones

\begin{tabular}{|l|l|l|l|l|l|l|l|l|}
\hline & NZ & CZ & EZ & SZ & WZ & NWZ & SWZ & Total \\
\hline Entire Period & 492 & 504 & 408 & 571 & 450 & 415 & 403 & 484 \\
\hline Period - 1 & 543 & 524 & 595 & 751 & 764 & 773 & 300 & 605 \\
\hline Period - 2 & 617 & 606 & 541 & 653 & 480 & 418 & 474 & 586 \\
\hline Period - 3 & 412 & 443 & 340 & 504 & 326 & 247 & 283 & 401 \\
\hline Period - 4 & 527 & 467 & 435 & 548 & 496 & 421 & 442 & 487 \\
\hline
\end{tabular}

Note: Sex ratio $=$ females 1000 males

Studies have also shown predominance of males among those infected by COVID-19. We see this pattern even in Ahmedabad, during all lockdown periods as well as across all the zones. Table 2 gives sex ratios among the infected persons, which is on an average 484 over the entire period ( $36.2 \%$ women). The only explanation is men are more mobile than women. Since COVID19 spreads through contact, those who are more mobile and move out of house have higher chances of getting infected. During the strict lockdown, when even men was restricted, the sex ratios among those infected increased to reaching 600. In other words, in close confines, the COVID-19 spread also to women. For better understanding of the sex ratio among the infected population, we need to refer to the city's sex ratio, which was 898 in 2011. Thus, for all zones and over all the periods, the sex ratio of those reporting COVID-19 infections, was less than that of the city. 


\section{Geography of Infections}

The geography of infections is mapped by the seven administrative zones of the city. With the SWZ and the NWZ being the peripheral areas of Ahmedabad, added to the AMC in 2006, has sparser population than the rest of the zones. In particular, the NWZ has elite gated communities that were strictly closed for the visitors during the first two months of the lockdown.

The CZ is the walled city (with narrow lanes and contiguous houses called pol) and its surrounding areas are closed textile mills and associated industries along with industrial workers' housing (called chali) and slums. This zone had the largest proportion (18.8\% of the total) (Table 3 ) of registered infections in the study period. When the first lockdown was imposed, this zone reported $46.4 \%$ of the total infections (period 26-03-2020 to 21-04-2020), which then went down to $36.5 \%$ in the next period and finally to $8.3 \%$ in the unlock period (01-06-2020 to 14-07-2020). The SZ, comprising dalit and muslim dominated areas of Ahmedabad including large informal settlements on the city's periphery (Hirway \& Mahadevia, 2020; Mahadevia et al., 2014) come second, wherein $17.7 \%$ of the total infections in the study period were reported but $29.9 \%$ of the total reported infections in Period 1, 24.6\% in Period 2 and declining to $13.6 \%$ in Period 5.

The NZ and the EZ have large proportion of informal settlements and houses the working class of the city, and has reported $17.0 \%$ and $15.4 \%$ of the total infections over the study period, but, reported higher numbers in the Periods 3, 4 and 5; NZ reporting highest proportion among the seven zones in Period 4 (a quarter of all reported infections in the AMC) and the EZ reporting higher proportions (around 18\%) in Periods 4 and 5. The unlock period had controls continuing in the central and south zones while other zones experienced opening up.

Table 3: Zonewise and Lockdown Phasewise Proportion of Infections (\%)

\begin{tabular}{|l|c|c|c|c|c|c|c|c|}
\hline & NZ & CZ & EZ & SZ & WZ & NWZ & SWZ & Total \\
\hline Entire period (17-03-2020 to 14-07-2020) & 17 & 18.6 & 15.4 & 17.7 & 15.8 & 8.2 & 7.2 & 100 \\
\hline Period 1 (26-03-2020 to 21-04-2020) & 5.4 & 46.4 & 5.1 & 29.9 & 7.4 & 3 & 3 & 100 \\
\hline Period 2 (16-04-2020 to 10-05-2020) & 12.3 & 36.5 & 9.9 & 24.6 & 9 & 4.2 & 3.5 & 100 \\
\hline Period 3 (04-05-2020 to 24-05-2020) & 20 & 23.7 & 13.7 & 21.5 & 11.1 & 4.9 & 5.1 & 100 \\
\hline Period 4 (18-05-2020 to 07-06-2020) & 25.1 & 14.8 & 17.8 & 16.1 & 13.8 & 6.2 & 6.1 & 100 \\
\hline Period 5 (01-06-2020 to 14-07-2020) & 16.7 & 8.3 & 17.9 & 13.6 & 21.2 & 12.3 & 10 & 100 \\
\hline
\end{tabular}

Note: In pre-lockdown period there were only 8 reported cases, 1 in NZ, 2 in CZ, 2 in WZ and 3 in $S W Z$.

In Table 3 we can see that the Periods 1 and 2 are dominated by the numbers in $\mathrm{CZ}$ and SZ; Period 3 sees NZ rising and CZ and SZ drastically reducing their share; Period 4 belongs to NZ and period 5 to WZ. Periods 4 and 5 also see rising shares of WZ, SWZ and NWZ. Prolonged periods of lockdown in the CZ and SZ brought down the infections after mid-May 2020. In the early period of the lockdown, given high density in the localities in these zones, the infections would have spread within the household or a residential settlement or a pol in the old city itself. Recent studies also show that there are more chances of the COVID-19 infection spreading within a household, that is among co-habiting people than among others ${ }^{20}$ or within the household or extended household (based on a study in Guangzhou, China; Jing et al 2020). Quarantining

20 See: https://timesofindia.indiatimes.com/life-style/health-fitness/health-news/do-you-know-how-quickly-coronaviruscan-spread-within-the-household/articleshow/76465866.cms (accessed on July 26, 2020). 
infected persons reduce the chance of infection among other household members (based on data from two hospitals in towns near Wuhan, one Zaoyang and another Chibi (Li et al., 2020), but if the house is small and the entire family is living in one-room, there is no quarantine facility. Hence, during the lockdown period, the infections spread rapidly in the dense and crowded localities, which are in CZ and SZ (explained later)

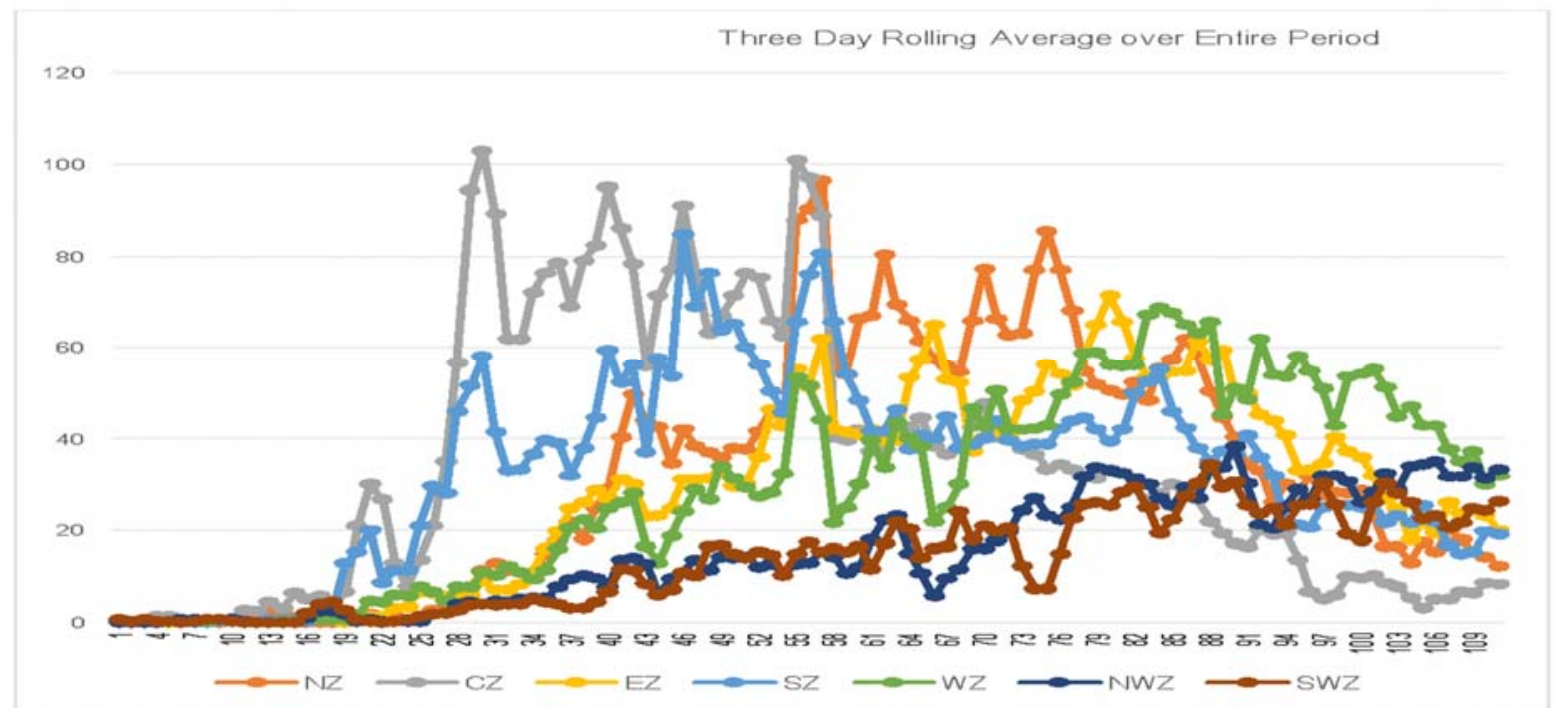

Figure 4 Three Day Rolling Average over Entire Period (March 17 - July 14, 2020)

When the lockdown was relaxed in certain parts of the city, largely the western part of the city, which has low density, the spread of infections seems to have occurred due to increased contact due to increased mobility of people. In WZ, NWZ and parts of SWZ, the housing is formal, with households living in more than three room housing. In the last two periods, Period 4 and 5, it seems that the infections have spread to households that are not living in high density areas or highly crowed areas. In fact, the infection in the Period 4 has spread to non-poor households as seen above. Figure 4 shows the three-day rolling average of infections by each zone. Panels 1 and 2 show the daily infections by each zone during five Periods described above and daily infections normalized over 100,000 population. 
Panel 1: Daily Infections by Zone
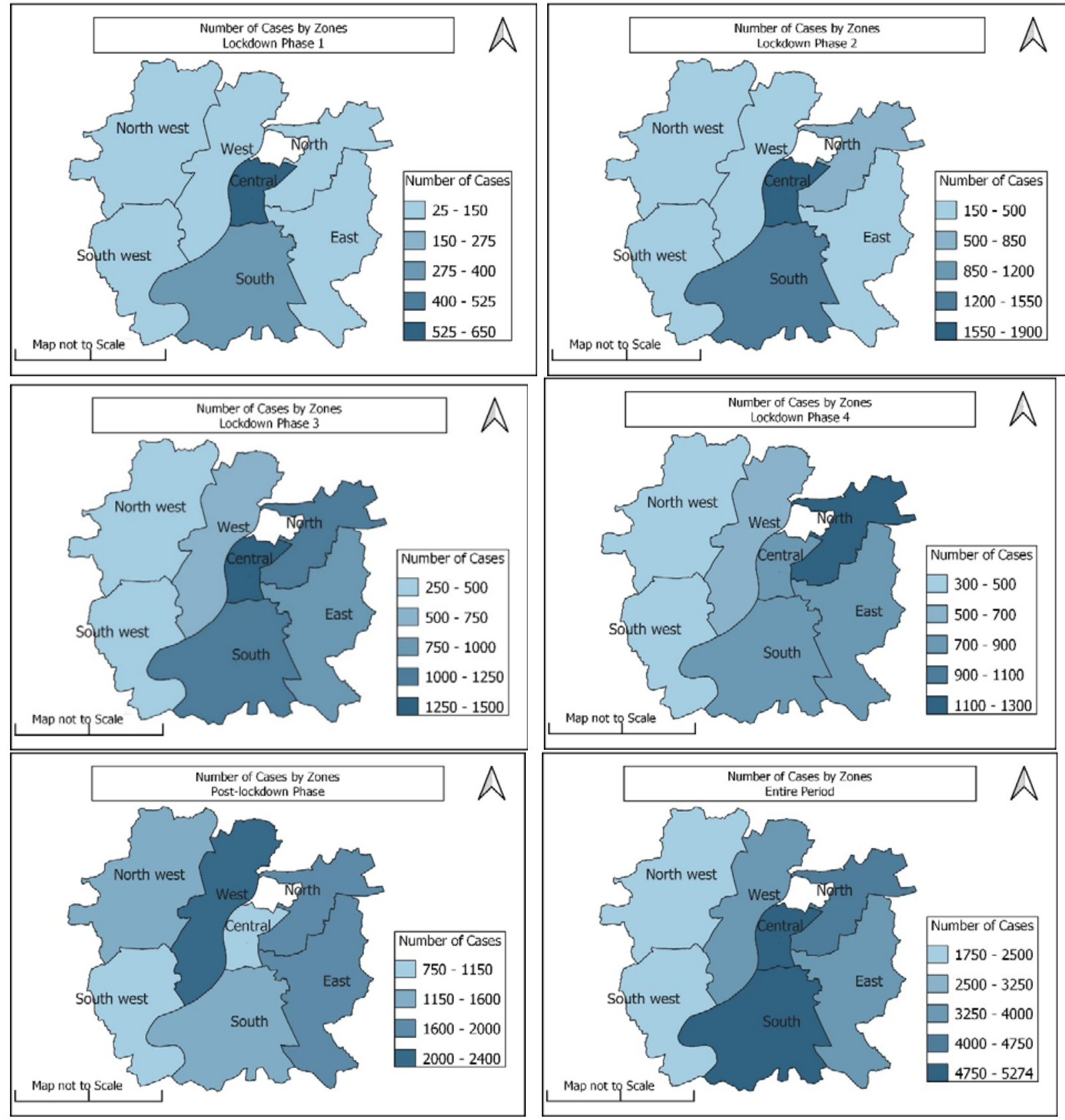
Panel 2: Daily Infections per 100,000 population by Zones

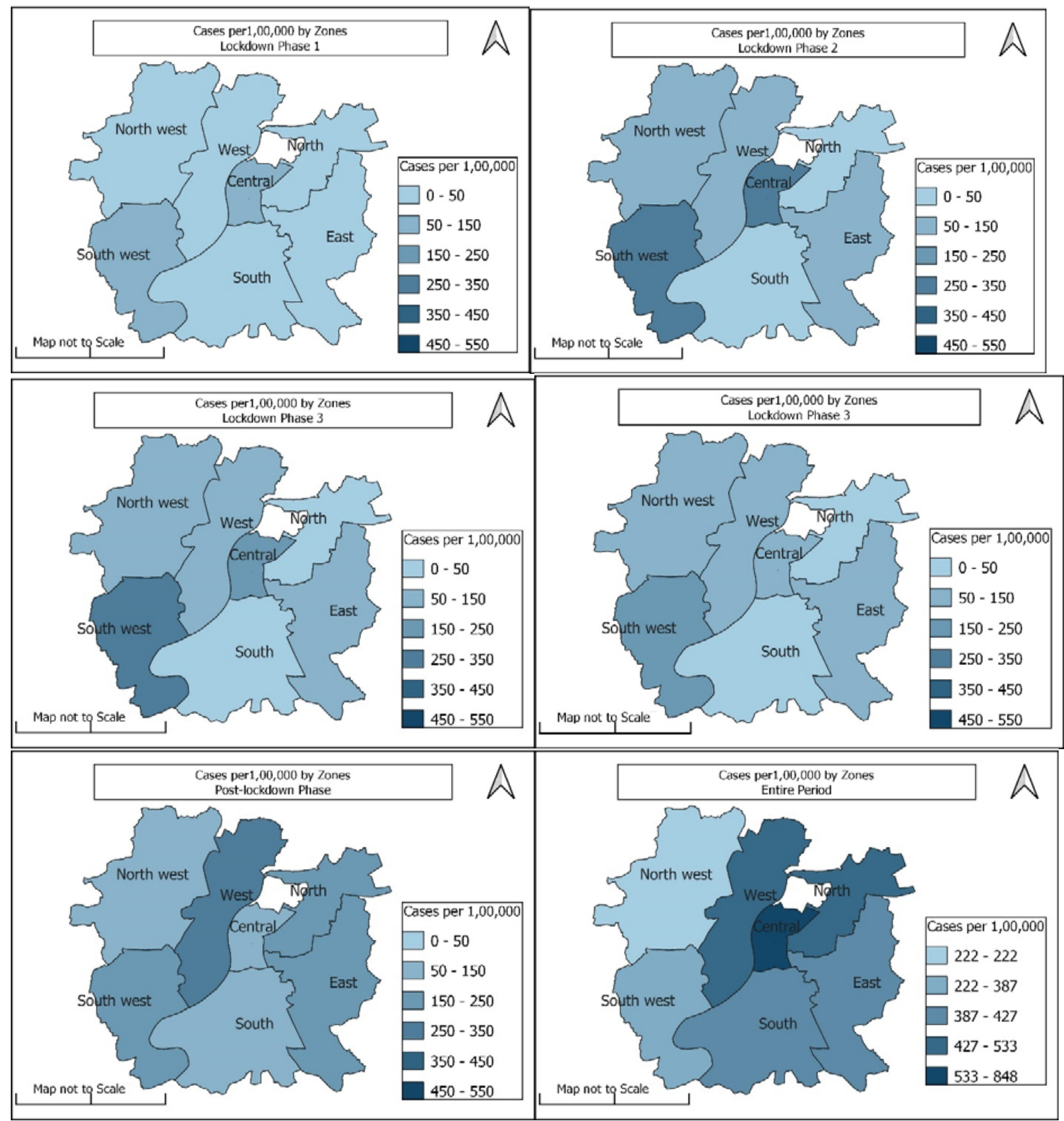




\section{$5 \quad$ Explanation of Unequal Infection Geographies}

The data was aggregated to 56 census wards in the city. Correlations between COVID-19 infection and density (an indicator of macro crowding), household size (an indicator of micro-crowding), and water availability in household were done as shown in Figure 5. Although the correlations are not statistically significant, the direction of the correlation is in the expected direction. Overcrowding at micro scale, expressed by density in person per square km, increases COVID-19 infections are expected to increase, as higher density increases the changes of transmitting COVID19 infections. At a micro-level, as overcrowding increases, that number of people living in a household or proportion of households with higher household size increases, COVID-19 infections are expected to increase (see Fig 5).
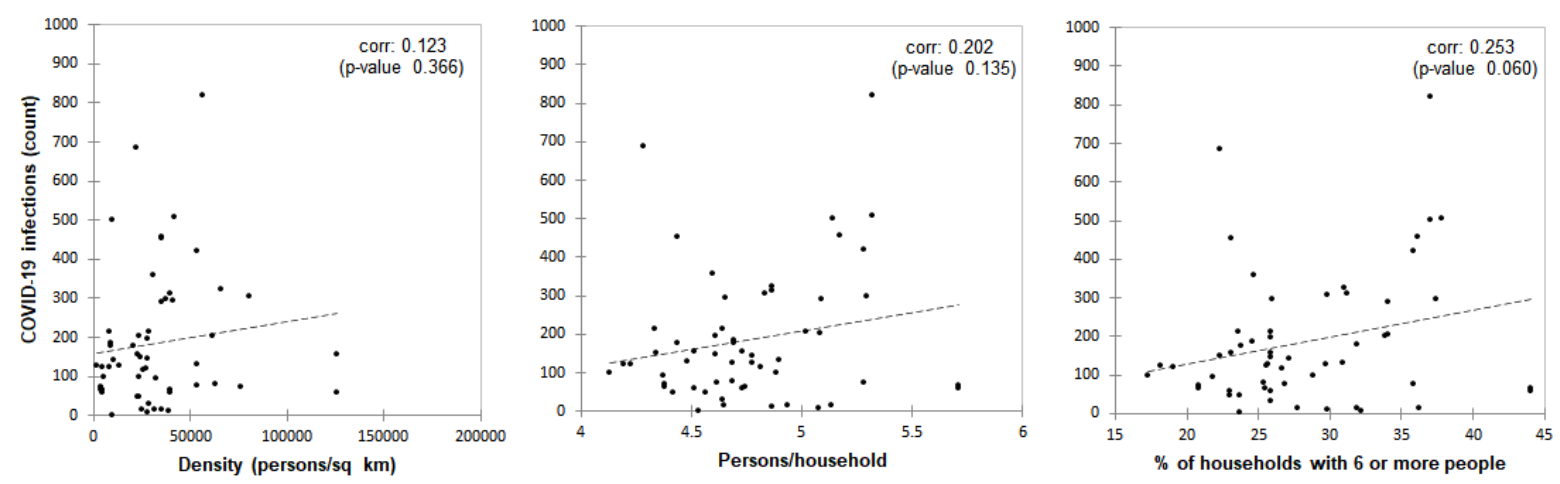

Figure 5: Correlations (r) between COVID-19 infections and density, average household size, \% households with 6 or more people

Correlation of COVID-19 infections were carried out by lockdown period with density and indicators of overcrowding, namely households with more than 6 persons living disaggregated by lockdown period. As the proportion of households with four or less people increase the COVID-19 infections drop during lockdown 1 and 2 together $(\mathrm{r}=-0.237$ and $\mathrm{p}$-value 0.079$)$. As the proportion of households with more than six persons increase the COVID-19 infections increase for lockdown 1 and 2 together $(r=0.266$ and p-value 0.048$)$. Thus, while for the overall period, the correlations of population density and crowding (represented by household size, $\%$ households with more than 6 people) or obverse of crowding (\% households with four or less persons), these show strong correlation for the lockdown phase $1+2$. The overall density and housing crowding do not show strong correlation because the conditions of lockdown varied spatially. Also, in the WZ, NWZ and SWZ, that had less stringent lockdown measures, these saw higher spread of infections from Period 4 onwards, leading to the impact of density and crowding observed only in the first two lockdown periods. 


\section{Discussion: Short-term and Long-term Policy Implications and Areas of Further Research}

This is the first paper that attempts to link the epidemiology of the COVID-19 virus infection, socio-economic characteristics, and its geography at an individual city level. The findings of this city level study, corroborate what is known of the infection's high prevalence among the elderly, working population and males. Similar studies for other Indian cities would be useful to generalize the behaviour of this virus and hence its control in the future.

The containment of the spread of virus, as suggested by evidence from Ahmedabad, has both short-term as well as long-term policy implications. The short-term policy implication for controlling the spread of COVID-19 (or any other virus in the future), in Indian cities as well as the global south, with high levels of overall as well as housing poverty, pervasive inequalities, high densities, inadequate water and sanitation coverage and lagging healthcare facilities, need to be thought about. These conditions are unlikely to change in a short time. This study shows that the lockdown as a mechanism of containment did work in highly dense areas. When the areas with low population density and low case numbers were opened, the virus spread to these areas. Thus, the spread of infection is as much a function of population density and housing crowding as of the manner in which the spread of is managed.

A good example of containing the spread and eventually reduce the COVID-19 infections is in the largest and the densest slum of the world, Dharavi in Mumbai, with a population density of 350,000 persons per sq $\mathrm{km}^{21}$. When the infections were noticed in Dharavi, the local government, started aggressive testing through door-to-door surveys, identifying both symptomatic as well as asymptomatic infections, tracing their contacts and testing the contact, and quarantining the infected in the Covid Care Centres. Two types of Centres were created, one for those who were asymptomatic or had mild symptoms and other for those with serious patients with all healthcare facilities $^{22}$. Brihanmumbai Municipal Corporation (BMC) distributed 125,000 people from Dharavi in over 48 containment zones, screened over 62,500 people via door-to-door surveys, fever camps, and medical clinics of private doctors and conducted 1,530 tests so far in the slum. Community toilets are sanitized daily ${ }^{23}$.

The long-term addressal of infections such as COVID-19 would be to not just pay attention to addressing housing security for all and improving the living conditions of the slum and squatter settlements but also deal with improving living conditions in the heritage areas, such as the Central Zone in Ahmedabad. In addition, local level planning interventions such as creating public shelters to quarantine infected persons during epidemics or pandemics would help in isolating and treating those infected. Given that for time to come, Indian cities would continue to have multigenerational families, such shelters would be required. These shelters can also be used during local heat waves which are also expected due to increasing global average temperatures on account of the climate change impacts and also floods caused during the monsoons.

\footnotetext{
21 https://www.hindustantimes.com/india-news/inside-dharavi-india-s-largest-slum-and-a-major-covid-hotspot/storyZbX5VOngcJlmsK9F4ohBvM.html (accessed on September 9, 2020).

22 https://www.outlookindia.com/website/story/india-news-dharavis-covid-19-containment-an-example-of-clinicalmanagement-medical-education-secretary/356480 (accessed on September 9, 2020).

23 https://www.hindustantimes.com/india-news/inside-dharavi-india-s-largest-slum-and-a-major-covid-hotspot/storyZbX5VOngcJlmsK9F4ohBvM.html (accessed on September 9, 2020).
} 
Lastly, further research is essential with regards to the patterns of COVID-19 infections in more cities in India. There is a requirement to also document approaches at the city level that have helped in containing the spread of this pandemic. The city level infection data should be made available for such analysis so that the Indian cities are well prepared to address not just the possible second wave of COVID-19 infection but also any other epidemic or pandemic in the future.

\section{References}

Antwi-Amoabeng, D., Beutler, B. D., Awad, M., Kanji, Z., Mahboob, S., Ghuman, J., Boppana, S. H., Sheikh, M. S., Ulanja, M. B., \& Gullapalli, N. (2020). Sociodemographic predictors of outcomes in COVID-19: examining the impact of ethnic disparities in Northern Nevada. MedRxiv, 2020.05.24.20112094. https://doi.org/10.1101/2020.05.24.20112094

Arif, M., \& Sengupta, S. (2020). Nexus between population density and COVID-19 pandemic in the south Indian states: A geo-statistical approach [Preprint]. SocArXiv. https://doi.org/10.31235/osf.io/e8nda

Chan, J. F.-W., Yuan, S., Kok, K.-H., To, K. K.-W., Chu, H., Yang, J., Xing, F., Liu, J., Yip, C. C.-Y., Poon, R. W.-S., Tsoi, H.-W., Lo, S. K.-F., Chan, K.-H., Poon, V. K.-M., Chan, W.-M., Ip, J. D., Cai, J.-P., Cheng, V. C.-C., Chen, H., .. Yuen, K.-Y. (2020). A familial cluster of pneumonia associated with the 2019 novel coronavirus indicating person-to-person transmission: a study of a family cluster. The Lancet, 395(10223), 514-523. https://doi.org/10.1016/S0140-6736(20)30154-9

Chandramouli, C., \& General, R. (2011). Census of india 2011. Provisional Population Totals. New Delhi: Government of India, 409-413.

Chatterjee, P., Nagi, N., Agarwal, A., Das, B., Banerjee, S., Sarkar, S., Gupta, N., \& Gangakhedkar, R. R. (2020). The 2019 novel coronavirus disease (COVID-19) pandemic: A review of the current evidence. Indian Journal of Medical Research, 151(2), 147. https://doi.org/10.4103/ijmr.IJMR_519_20

Das, A., Ghosh, S., Das, K., Dutta, I., Basu, T., \& Das, M. (2020). Re:(In) visible impact of inadequate WaSH Provision on COVID-19 incidences can be not be ignored in large and megacities of India. Public Health, 185, 34-36. https://doi.org/10.1016/j.puhe.2020.05.035

Davies, N. G., Klepac, P., Liu, Y., Prem, K., Jit, M., \& Eggo, R. M. (2020). Age-dependent effects in the transmission and control of COVID-19 epidemics. Nature Medicine, 26(8), 1205-1211. https://doi.org/10.1038/s41591-020-0962-9

Doremalen, N. van, Bushmaker, T., Morris, D. H., Holbrook, M. G., Gamble, A., Williamson, B. N., Tamin, A., Harcourt, J. L., Thornburg, N. J., Gerber, S. I., Lloyd-Smith, J. O., Wit, E. de, \& Munster, V. J. (2020, March 17). Aerosol and Surface Stability of SARS-CoV-2 as Compared with SARS-CoV-1 [Letter]. In New England Journal of Medicine (world). Massachusetts Medical Society. https://doi.org/10.1056/NEJMc2004973

Ezeh, A., Oyebode, O., Satterthwaite, D., Chen, Y.-F., Ndugwa, R., Sartori, J., Mberu, B., Melendez-Torres, G. J., Haregu, T., Watson, S. I., Caiaffa, W., Capon, A., \& Lilford, R. J. (2017). The history, geography, and sociology of slums and the health problems of people who live in slums. The Lancet, 389(10068), 547-558. https://doi.org/10.1016/S0140-6736(16)31650-6

Fauci, A. S., Lane, H. C., \& Redfield, R. R. (2020). Covid-19 - Navigating the Uncharted. New England Journal of Medicine, 382(13), 1268-1269. https://doi.org/10.1056/NEJMe2002387

Gu, C., Jiang, W., Zhao, T., \& Zheng, B. (2020). Mathematical Recommendations to Fight Against COVID-19 (SSRN Scholarly Paper ID 3551006). Social Science Research Network. https://doi.org/10.2139/ssrn.3551006

Guan, W., Ni, Z., Hu, Y., Liang, W., Ou, C., He, J., Liu, L., Shan, H., Lei, C., Hui, D. S., Du, B., Li, L., Zeng, G., Yuen, K.-Y., Chen, R., Tang, C., Wang, T., Chen, P., Xiang, J., ... Zhong, N. (2020). Clinical characteristics of 2019 novel coronavirus infection in China. MedRxiv, 2020.02.06.20020974. https://doi.org/10.1101/2020.02.06.20020974 
He, X., Lau, E. H. Y., Wu, P., Deng, X., Wang, J., Hao, X., Lau, Y. C., Wong, J. Y., Guan, Y., Tan, X., Mo, X., Chen, Y., Liao, B., Chen, W., Hu, F., Zhang, Q., Zhong, M., Wu, Y., Zhao, L., ... Leung, G. M. (2020). Temporal dynamics in viral shedding and transmissibility of COVID-19. Nature Medicine, 26(5), 672-675. https://doi.org/10.1038/s41591-020-0869-5

Hirway, I., \& Mahadevia, D. (2020, April 29). Why Is Gujarat a COVID-19 Hotspot? The Wire Science. https://science.thewire.in/health/why-is-gujarat-a-covid-19-hotspot/

Hood, E. (2005). Dwelling Disparities: How Poor Housing Leads to Poor Health. Environmental Health Perspectives, 113(5), A310-A317.

Jayaweera, M., Perera, H, Gunawardana, B \& Mantunge, J. (2020). Transmission of COVID-19 virus by droplets and aerosols: A critical review on the unresolved dichotomy. Environ Res. 2020 Sep; 188: 109819. doi: 10.1016/j.envres.2020.109819.

Li, W., Zhang, B., Lu, J., Liu, S., Chang, Z., Peng, C., Liu, X., Zhang, P., Ling, Y., Tao, K., \& Chen, J. (2020). Characteristics of Household Transmission of COVID-19. Clinical Infectious Diseases. https://doi.org/10.1093/cid/ciaa450

Mahadevia, D., Desai, R. \& Vyas, S. (2014). City Profile: Ahmedabad. Centre for Urban Equity, CEPT University.

Mishra, S. V., Gayen, A., \& Haque, S. M. (2020). COVID-19 and urban vulnerability in India. Habitat International, 103, 102230.

Patel, A. (2020). Preventing COVID-19 Amid Public Health and Urban Planning Failures in Slums of Indian Cities. World Medical \&3 Health Policy, n/a(n/a). https://doi.org/10.1002/wmh3.351

Patel, A., Koizumi, N., \& Crooks, A. (2014). Measuring slum severity in Mumbai and Kolkata: A householdbased approach. Habitat International, 41, 300-306. https://doi.org/10.1016/j.habitatint.2013.09.002

Patel, A., Shah, P., \& Beauregard, B. E. (2020). Measuring multiple housing deprivations in urban India using Slum Severity Index. Habitat International, 101, 102190. https://doi.org/10.1016/j.habitatint.2020.102190

Pollán, M., Pérez-Gómez, B., Pastor-Barriuso, R., Oteo, J., Hernán, M. A., Pérez-Olmeda, M., Sanmartín, J. L., Fernández-García, A., Cruz, I., Larrea, N. F. de, Molina, M., Rodríguez-Cabrera, F., Martín, M., MerinoAmador, P., Paniagua, J. L., Muñoz-Montalvo, J. F., Blanco, F., Yotti, R., Blanco, F., ... Villa, A. V. de la. (2020). Prevalence of SARS-CoV-2 in Spain (ENE-COVID): a nationwide, population-based seroepidemiological study. The Lancet, 396(10250), 535-544. https://doi.org/10.1016/S0140-6736(20)314835

Khatua, S. (2020). Density, Distancing, Informal Settlements and the Pandemic. Economic and Political Weekly, 55(20), 7-8.

Sarkar, B., Sinha, R. N., \& Sarkar, K. (2020). Initial viral load of a COVID-19-infected case indicated by its cycle threshold value of polymerase chain reaction could be used as a predictor of its transmissibility - An experience from Gujarat, India. Indian Journal of Community Medicine, 45(3), 278. https://doi.org/10.4103/ijcm.IJCM_593_20

Singh, R., \& Adhikari, R. (2020). Age-structured impact of social distancing on the COVID-19 epidemic in India. ArXiv:2003.12055 [Cond-Mat, q-Bio]. http://arxiv.org/abs/2003.12055

Tian, H., Liu, Y., Li, Y., Wu, C.-H., Chen, B., Kraemer, M. U. G., Li, B., Cai, J., Xu, B., Yang, Q., Wang, B., Yang, P., Cui, Y., Song, Y., Zheng, P., Wang, Q., Bjornstad, O. N., Yang, R., Grenfell, B. T., ... Dye, C. (2020). An investigation of transmission control measures during the first 50 days of the COVID-19 epidemic in China. Science, 368(6491), 638-642. https://doi.org/10.1126/science.abb6105

UN-HABITAT. (2020). UN-Habitat COVID-19 Response Plan $\quad$ (p. 16). https://unhabitat.org/sites/default/files/2020/04/final_un-habitat_covid-19_response_plan.pdf

WHO. (2020). Coronavirus disease 2019 (COVID-19) Situation Report (No. 40). https://www.who.int/docs/default-source/coronaviruse/situation-reports/20200229-sitrep-40-covid19.pdf?sfvrsn=849d0665_2

Wilder-Smith, A., \& Freedman, D. O. (2020). Isolation, quarantine, social distancing and community containment: pivotal role for old-style public health measures in the novel coronavirus (2019-nCoV) outbreak. Journal of Travel Medicine, 27(2). https://doi.org/10.1093/jtm/taaa020 